\title{
Study Branch
}

National Cancer Institute

\section{Source}

National Cancer Institute. Study Branch. NCI Thesaurus. Code C142701.

A planned point in time within the study design in which there is a subdivision of subjects

to particular procedures or treatment groups. 